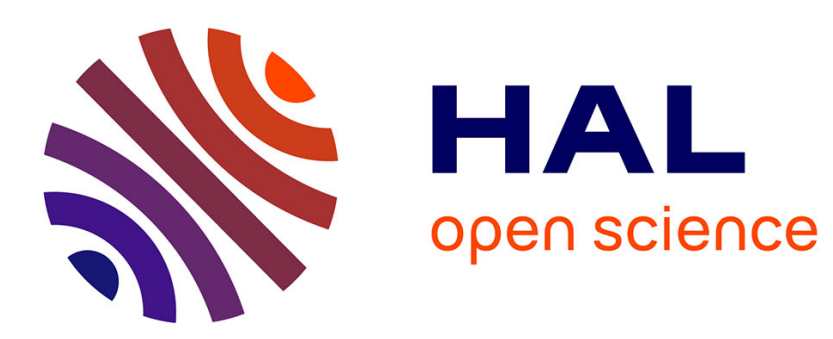

\title{
Temperature-Dependent Kinetic Study of the Reaction of Hydroxyl Radicals with Hydroxyacetone
}

Yuri Bedjanian

\section{To cite this version:}

Yuri Bedjanian. Temperature-Dependent Kinetic Study of the Reaction of Hydroxyl Radicals with Hydroxyacetone. Journal of Physical Chemistry A, 2020, 124 (14), pp.2863-2870. 10.1021/acs.jpca.0c00429 . hal-02559832

\section{HAL Id: hal-02559832 \\ https://hal.science/hal-02559832}

Submitted on 3 Dec 2020

HAL is a multi-disciplinary open access archive for the deposit and dissemination of scientific research documents, whether they are published or not. The documents may come from teaching and research institutions in France or abroad, or from public or private research centers.
L'archive ouverte pluridisciplinaire $\mathbf{H A L}$, est destinée au dépôt et à la diffusion de documents scientifiques de niveau recherche, publiés ou non, émanant des établissements d'enseignement et de recherche français ou étrangers, des laboratoires publics ou privés. 


\title{
Temperature-Dependent Kinetic Study of the Reaction of Hydroxyl Radical with Hydroxyacetone
}

\begin{abstract}
Yuri Bedjanian
Institut de Combustion, Aérothermique, Réactivité et Environnement (ICARE), CNRS 45071 Orléans Cedex 2, France
\end{abstract}

Corresponding author: Tel.: +33 238255474, Fax: +33 238696004, e-mail: yuri.bedjanian@cnrsorleans.fr 


\section{ABSTRACT}

The kinetics of the reaction of $\mathrm{OH}$ radicals with hydroxyacetone has been investigated as a function of temperature at $(2.0-2.1)$ Torr total pressure of helium and over an extended temperature range, $\mathrm{T}=250-830 \mathrm{~K}$, and as a function of pressure at $\mathrm{T}=301 \mathrm{~K}$ in the pressure range 1.0-10.4 Torr. The rate constant of the reaction $\mathrm{OH}+\mathrm{CH}_{3} \mathrm{C}(\mathrm{O}) \mathrm{CH}_{2} \mathrm{OH} \rightarrow$ products (1) was measured using both absolute (from the kinetics of $\mathrm{OH}$ consumption in excess of hydroxyacetone) and relative rate method, $k_{1}=4.7 \times 10^{-22} \times T^{3.25} \exp (1410 / \mathrm{T})$ $\mathrm{cm}^{3}$ molecule $\mathrm{s}^{-1}$ at $\mathrm{T}=250-830 \mathrm{~K}$. The present data combined with selected previous temperature dependent studies of reaction (1) yield $k_{1}=4.4 \times 10^{-20} \times T^{2.63} \exp (1110 / \mathrm{T})$ $\mathrm{cm}^{3}$ molecule $\mathrm{s}^{-1}$, which is recommended from the present work at $\mathrm{T}=230-830 \mathrm{~K}$ (with conservative uncertainty of $20 \%$ at all temperatures). $k_{1}$ was found to be pressure independent in the pressure range from 1.0 to 10.4 Torr of $\mathrm{He}$ at $\mathrm{T}=301 \mathrm{~K}$. The present results are compared with previous experimental and theoretical data. 


\section{INTRODUCTION}

Hydroxyacetone $\left(\mathrm{CH}_{3} \mathrm{C}(\mathrm{O}) \mathrm{CH}_{2} \mathrm{OH}\right)$ is the simplest representative of hydroxyketones, chemical species belonging to a large family of Oxygenated Volatile Organic Compounds (OVOC) playing an important role in the tropospheric chemistry. ${ }^{1}$ Hydroxyacetone (HAC) is one of the most abundant OVOC in the atmosphere due to important biogenic emissions ${ }^{2}$ and in situ production in atmospheric oxidation of isoprene $\mathrm{e}^{3-5}$ and its major $\mathrm{OH}$-initiated oxidation product, methacrolein. ${ }^{5-6}$ The atmospheric degradation of hydroxyketones is triggered by their photolysis and reactions with atmospheric oxidants $\left(\mathrm{OH}, \mathrm{NO}_{3}, \mathrm{O}_{3}, \mathrm{Cl}\right)$, mainly with $\mathrm{OH}$ radical. ${ }^{1}$ The understanding of the atmospheric chemistry of hydroxyketones requires information on their major photo-oxidation routs, including kinetics of their reactions with the atmospheric oxidants. Reactions of $\mathrm{OH}$ radicals with hydroxyketones proceed through a complex kinetic mechanism leading to a non-Arrhenius behavior of the reaction rate constant, $^{7-8}$ and in this respect, are of great interest for the theory. The existing data base on the reactions of hydroxyketones with $\mathrm{OH}$ is mainly limited to a number of relative rate measurements at room temperature. ${ }^{1}$ In our recent paper, we have reported the temperature dependence of the rate constant for the reaction of $\mathrm{OH}$ with 3-hydroxy-3-methyl-2-butanone in the temperature range $278-830 \mathrm{~K}^{7}$

The reaction of $\mathrm{OH}$ with hydroxyacetone

$$
\mathrm{OH}+\mathrm{CH}_{3} \mathrm{C}(\mathrm{O}) \mathrm{CH}_{2} \mathrm{OH} \rightarrow \text { products }
$$

has been quite extensively studied both experimentally ${ }^{8-14}$ and theoretically. ${ }^{8,13-15}$ Theoretical calculations $^{8,13-15}$ showed that reaction (1) proceeds through pre-reactive hydrogen-bonded complexes

$$
\mathrm{OH}+\mathrm{HAC} \leftrightarrows \mathrm{OH} \cdot \mathrm{HAC} * \leftrightarrows \mathrm{OH} \cdot \mathrm{HAC} \rightarrow \text { products }
$$

where $\mathrm{OH} \bullet \mathrm{HAC}^{*}$ and $\mathrm{OH} \bullet \mathrm{HAC}$ denote excited and collisionally thermalized $\mathrm{OH}$ hydroxyacetone complexes, respectively. The reaction of hydroxyacetone with $\mathrm{OH}$ radical is supposed to proceed mainly by $\mathrm{H}$-atom abstraction from $\mathrm{CH}_{2}$ group, ${ }^{10,13-15}$

$$
\mathrm{OH}+\mathrm{CH}_{3} \mathrm{C}(\mathrm{O}) \mathrm{CH}_{2} \mathrm{OH} \rightarrow \mathrm{CH}_{3} \mathrm{C}(\mathrm{O}) \mathrm{CHOH}+\mathrm{H}_{2} \mathrm{O}
$$

two other reaction channels, corresponding to $\mathrm{H}$-atom abstraction from $\mathrm{CH}_{3}$ and $\mathrm{OH}$ groups, being insignificant $(<1 \%$ at $\mathrm{T}=298 \mathrm{~K}):^{15}$

$$
\begin{array}{ll}
\mathrm{OH}+\mathrm{CH}_{3} \mathrm{C}(\mathrm{O}) \mathrm{CH}_{2} \mathrm{OH} \rightarrow & \mathrm{CH}_{2} \mathrm{C}(\mathrm{O}) \mathrm{CH}_{2} \mathrm{OH}+\mathrm{H}_{2} \mathrm{O} \\
\mathrm{OH}+\mathrm{CH}_{3} \mathrm{C}(\mathrm{O}) \mathrm{CH}_{2} \mathrm{OH} \rightarrow & \mathrm{CH}_{3} \mathrm{C}(\mathrm{O}) \mathrm{CH}_{2} \mathrm{O}+\mathrm{H}_{2} \mathrm{O}
\end{array}
$$

Despite the relatively large number of experimental studies of reaction (1), ${ }^{8-14}$ the value of the reaction rate constant at room temperature, temperature dependence of the rate constant 
and its potential pressure dependence is still an open question. The results of earlier room temperature measurements of $k_{1}{ }^{9-12}$ in the pressure range from 10 to 750 Torr, employing both absolute $e^{9,11-12}$ and relative rate ${ }^{10}$ methods, are consistent with each other and fall in the range $(2.5-3.5) \times 10^{-12} \mathrm{~cm}^{3}$ molecule $\mathrm{s}^{-1}$ with an average value of $k_{1}( \pm 2 \sigma)=(3.0 \pm 0.8) \times 10^{-12}$ $\mathrm{cm}^{3}$ molecule $\mathrm{s}^{-1}$ at $\mathrm{T}=298 \mathrm{~K}$. In two subsequent temperature dependent studies of reaction (1), negative and positive dependence of $k_{1}$ on temperature were reported by Dillon et al. at 60 Torr ${ }^{13}$ and Baasandorj et al. at 2-5 Torr of He, ${ }^{14}$ respectively. Besides, the value of $k_{1}$ at $\mathrm{T}=$ $298 \mathrm{~K}$ measured by Dillon et al. ${ }^{13}$ was by a factor of 2 higher compared with other studies. Finally, in the most recent temperature dependent study of reaction (1), $\mathrm{Vu}$ et $\mathrm{al}^{8}{ }^{8}$ have observed a transition in temperature dependence of $k_{1}$ from negative at $\mathrm{T}<380 \mathrm{~K}$ to positive at $\mathrm{T}=410-500 \mathrm{~K}$. Moreover, the authors observed a pronounced decrease of $k_{1}$ at total pressures lower than $\sim 45$ Torr at $\mathrm{T}=301 \mathrm{~K}$. Based on the experimental observations, $\mathrm{Vu}$ et al. ${ }^{8}$ proposed a reaction mechanism, which, according to the authors, reconciles the disparate $k_{1}$ high pressure data of Dillon et al. ${ }^{13}$ and those of Baasandorj et al. ${ }^{14}$ measured at low pressures.

The objective of the present low pressure study of reaction (1) was to measure the reaction rate constant in an extended temperature range $(250-830 \mathrm{~K})$ and verify the possible pressure dependence of $k_{1}$ at low pressures (1-10 Torr of He) in comparison with previous experimental data and theoretical predictions.

\section{EXPERIMENTAL}

The experimental setup consisted of a discharge flow reactor combined with a modulated molecular beam mass spectrometer. ${ }^{7,16-18}$ We have used two flow reactors. The first one, used at low temperatures $(250-336 \mathrm{~K})$, consisted of a Pyrex tube $(45 \mathrm{~cm}$ length and $2.4 \mathrm{~cm}$ i.d.) with a jacket for the thermostated liquid circulation (ethanol). The walls of this low temperature reactor were coated with halocarbon wax in order to reduce the heterogeneous loss of $\mathrm{OH}$. The second, high temperature, reactor used at $\mathrm{T}=310-830 \mathrm{~K}$, consisted of an uncoated electrically heated Quartz tube (45 cm length and $2.5 \mathrm{~cm}$ i.d.) with water-cooled attachments (Figure S1, Supporting Information, SI). ${ }^{16}$

Hydroxyl radicals were generated inside the movable injector in reaction of $\mathrm{H}$ atoms with excess $\mathrm{NO}_{2}\left(\left[\mathrm{NO}_{2}\right] \sim 10^{13}\right.$ molecule $\left.\mathrm{cm}^{-3}\right)$, hydrogen atoms being produced in a microwave discharge of $\mathrm{H}_{2} / \mathrm{He}$ mixtures (Figure $\mathrm{S} 1, \mathrm{SI}$ ):

$$
\mathrm{H}+\mathrm{NO}_{2} \rightarrow \mathrm{OH}+\mathrm{NO}
$$




$$
k_{2}=(1.47 \pm 0.26) \times 10^{-10} \mathrm{~cm}^{3} \text { molecule }{ }^{-1} \mathrm{~s}^{-1}(\mathrm{~T}=195-2000) .{ }^{19}
$$

$\mathrm{OH}$ radicals were scavenged with an excess of $\mathrm{Br}_{2}$ (added in the end of the reactor $5 \mathrm{~cm}$ upstream of the sampling cone, as shown in Figure S1, SI) through reaction 3 and detected at $\mathrm{m} / \mathrm{z}=96 / 98\left(\mathrm{HOBr}^{+}\right)$:

$$
\begin{aligned}
& \mathrm{OH}+\mathrm{Br}_{2} \rightarrow \mathrm{HOBr}+\mathrm{Br} \\
& k_{3}=2.16 \times 10^{-11} \exp (207 / \mathrm{T}) \mathrm{cm}^{3} \text { molecule }{ }^{-1} \mathrm{~s}^{-1}(\mathrm{~T}=220-950) .^{7}
\end{aligned}
$$

The absolute concentration of $\mathrm{OH}$ radicals was determined from the consumed fraction of $\left[\mathrm{Br}_{2}\right]$ upon $\mathrm{OH}$ conversion to $\mathrm{HOBr}$ in reaction 3: $[\mathrm{OH}]=[\mathrm{HOBr}]=\Delta\left[\mathrm{Br}_{2}\right]$. The method employed for $\mathrm{OH}$ detection and their absolute calibration was discussed in details in previous papers from this group. ${ }^{20-21}$

The hydroxyacetone was introduced into the reactor by flowing the bath gas $(\mathrm{He})$ over liquid hydroxyacetone and was detected by mass spectrometry at its parent peak at $\mathrm{m} / \mathrm{z}=74$ $\left(\mathrm{CH}_{3} \mathrm{C}(\mathrm{O}) \mathrm{CH}_{2} \mathrm{OH}^{+}\right)$. The water impurity in the gaseous samples of hydroxyacetone, directly monitored at $\mathrm{m} / \mathrm{z}=18\left(\mathrm{H}_{2} \mathrm{O}^{+}\right)$, was always less than $2.5 \%$. The absolute concentration of hydroxyacetone was determined through injection of known amounts $(0.2-1.0 \mu \mathrm{L})$ of HAC into a helium flow in the reactor and recording its parent peak intensity at $\mathrm{m} / \mathrm{z}=74$. The integrated area of the mass spectrometric signal, corresponding to known total number of HAC molecules injected into the reactor, allowed the determination of the calibration factor. The impact of the possible loss of HAC on the walls of the reactor on the results of the calibration experiments was considered as insignificant for the following reasons. Firstly, in the kinetic measurements, hydroxyacetone was introduced into the reactor through the movable injector (Figure S1, SI) and its kinetics could be directly monitored: we have not observed any measurable loss of HAC on the walls of the reactor in the whole temperature range of the study. Secondly, generally, calibration experiments consisted in several (4-5) successive injections of HAC: the integrated area of the mass spectrometric signal of HAC (normalized by the amount of HAC injected) from different injections were similar within $10 \%$. In addition, the calibration factors determined before the kinetic measurements (that is in the reactor not treated with hydroxyacetone and reaction products) were similar to those measured at the end of the kinetic experiments. Finally, the relationships between the HAC calibration factors and those of the non-sticky species $\left(\mathrm{Br}_{2}, \mathrm{NO}_{2}\right)$ determined at high and low temperatures (where the probable wall loss of HAC should be more effective) and in two reactors with different surfaces were similar. Absolute concentrations of $\mathrm{NO}_{2}, \mathrm{Br}_{2}$ and $\mathrm{n}$ - 
heptane were calculated from their flow rates obtained from the measurements of the pressure drop of their mixtures in He stored in calibrated volume flasks.

The purities of the gases used were as follows: He $>99.9995 \%$ (Alphagaz), passed through liquid nitrogen trap; $\mathrm{H}_{2}>99.998 \%$ (Alphagaz); $\mathrm{Br}_{2}>99.99 \%$ (Aldrich); $\mathrm{NO}_{2}>99 \%$ (Alphagaz); n-heptane $>99 \%$ (Aldrich); Hydroxyacetone $>95 \%$ (Alfa Aesar), degassed before use.

\section{RESULTS AND DISCUSSION}

3.1. Rate constant of reaction (1): absolute measurements. The rate constant of the title reaction was determined at total pressure of (2.0-2.1) Torr under pseudo-first order conditions monitoring $\mathrm{OH}$ decays in excess of hydroxyacetone. Temporal profiles of $\mathrm{OH}$ (Figures 1 and S2 $(\mathrm{SI})$ ) were fitted to an exponential function $[\mathrm{OH}]=[\mathrm{OH}]_{0} \times \exp \left(-k_{1}{ }^{\prime} \times \mathrm{t}\right)$, where $[\mathrm{OH}]_{0}$ and $[\mathrm{OH}]$ are the initial and time-dependent concentrations of $\mathrm{OH}$ radicals, respectively, and $k_{1}{ }^{\prime}=k_{1} \times[\mathrm{HAC}]+k_{\mathrm{w}}$ is the pseudo-first-order rate constant with $k_{\mathrm{w}}$ representing the wall loss of $\mathrm{OH}$ radicals, which could be measured in the absence of HAC in the reactor. In these experiments, the initial concentration of $\mathrm{OH}$ radicals was in the range (1.5 $-3.5) \times 10^{11}$ molecule $\mathrm{cm}^{-3}$; the ranges of hydroxyacetone concentrations are shown in Table 1.

Table 1. Summary of the Absolute Measurements of the Rate Constants of the Reaction $\mathrm{OH}+$ Hydroxyacetone.

$\begin{array}{lccc}T(\mathrm{~K}) & \text { Number of kinetic runs } & \begin{array}{c}{[\mathrm{HAC}]} \\ \left(10^{13} \text { molecule } \mathrm{cm}^{-3}\right)\end{array} & \begin{array}{c}k_{1}{ }^{a} \\ \left(10^{-12} \mathrm{~cm}^{3} \text { molecule }^{-1} \mathrm{~s}^{-1}\right)\end{array} \\ 298 & 12 & 0.40-6.64 & 6.03 \\ 330 & 10 & 0.23-5.69 & 5.18 \\ 336 & 10 & 0.25-5.68 & 5.32 \\ 370 & 10 & 0.17-5.66 & 4.73 \\ 425 & 11 & 0.20-4.21 & 4.41 \\ 500 & 16 & 0.17-6.94 & 4.64 \\ 565 & 11 & 0.13-6.18 & 5.20 \\ 630 & 11 & 0.15-5.08 & 5.76 \\ 715 & 9 & 0.32-4.85 & 6.90 \\ 830 & 9 & 0.15-5.09 & 7.59 \\ { }^{a} \text { Statistical uncertainty on } k_{1} \text { is } \leq 5 \% \text { and the total estimated uncertainty is approximately } 15 \% .\end{array}$




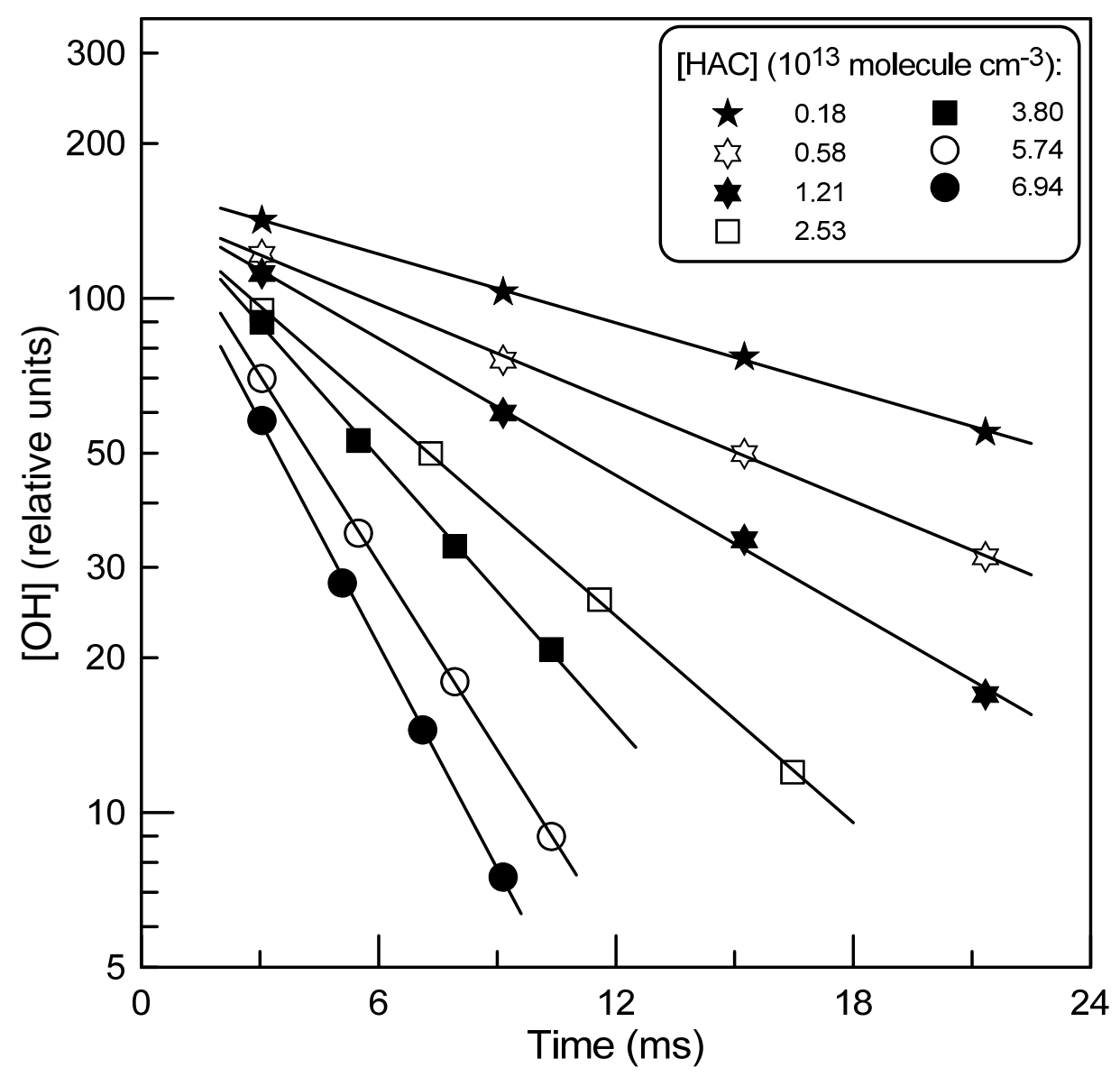

Figure 1. Examples of the kinetics of $\mathrm{OH}$ consumption in reaction with hydroxyacetone: $\mathrm{T}=500$ K.

The flow velocity in the reactor was in the range (1190-2190) $\mathrm{cm} \mathrm{s}^{-1}$. The consumption of hydroxyacetone in reaction (1) was insignificant due to its sufficiently high excess over $\mathrm{OH}$ radicals. The probable thermal decomposition of HAC at high temperatures of the study was also explored. Firstly, we have not observed any visible consumption of hydroxyacetone on the time scale of our experiments. The signals at $\mathrm{m} / \mathrm{z}=94 / 96,96 / 98,110 / 112$ and 122/124, corresponding to $\mathrm{CH}_{3} \mathrm{Br}, \mathrm{HOBr}, \mathrm{CH}_{2} \mathrm{BrOH}$ and $\mathrm{CH}_{3} \mathrm{C}(\mathrm{O}) \mathrm{Br}$, respectively, which could be formed in reactions of possible products of $\mathrm{HAC}$ decomposition in presence of $\mathrm{Br}_{2}$, were also analyzed. The concentrations of these species were estimated to be lower than $10^{11}$ molecule $\mathrm{cm}^{-3}$ at highest concentrations of HAC and highest temperatures of the study. Based on these observations, the thermal decomposition of hydroxyacetone could be considered as insignificant under experimental conditions of the study and not affecting the kinetic measurements.

Examples of the second-order plots at different temperatures are shown in Figures 2 and S3 (SI). The diffusion corrections, ${ }^{22}$ applied to all the measured values of $k_{1}$ ' using diffusion coefficient $D_{0}(\mathrm{OH}-\mathrm{He})=660 \times(\mathrm{T} / 298)^{1.85} \operatorname{Torr~}^{\mathrm{cm}} \mathrm{s}^{-1}$, $^{23}$ were generally within a few 
percent reaching up to $17 \%$ in several kinetic runs. One can note that in the experiments at $\mathrm{T}$ $=500 \mathrm{~K}$, the variation of the initial concentration of $\mathrm{OH}$ from 1.4 to $3.2 \times 10^{11}$ molecule $\mathrm{cm}^{-3}$ had no impact on the measured $k_{1}$ '. This indicates that the possible impact of secondary reactions of $\mathrm{OH}$ radicals on the measurements of $k_{1}$ was insignificant due to their low initial concentrations used.

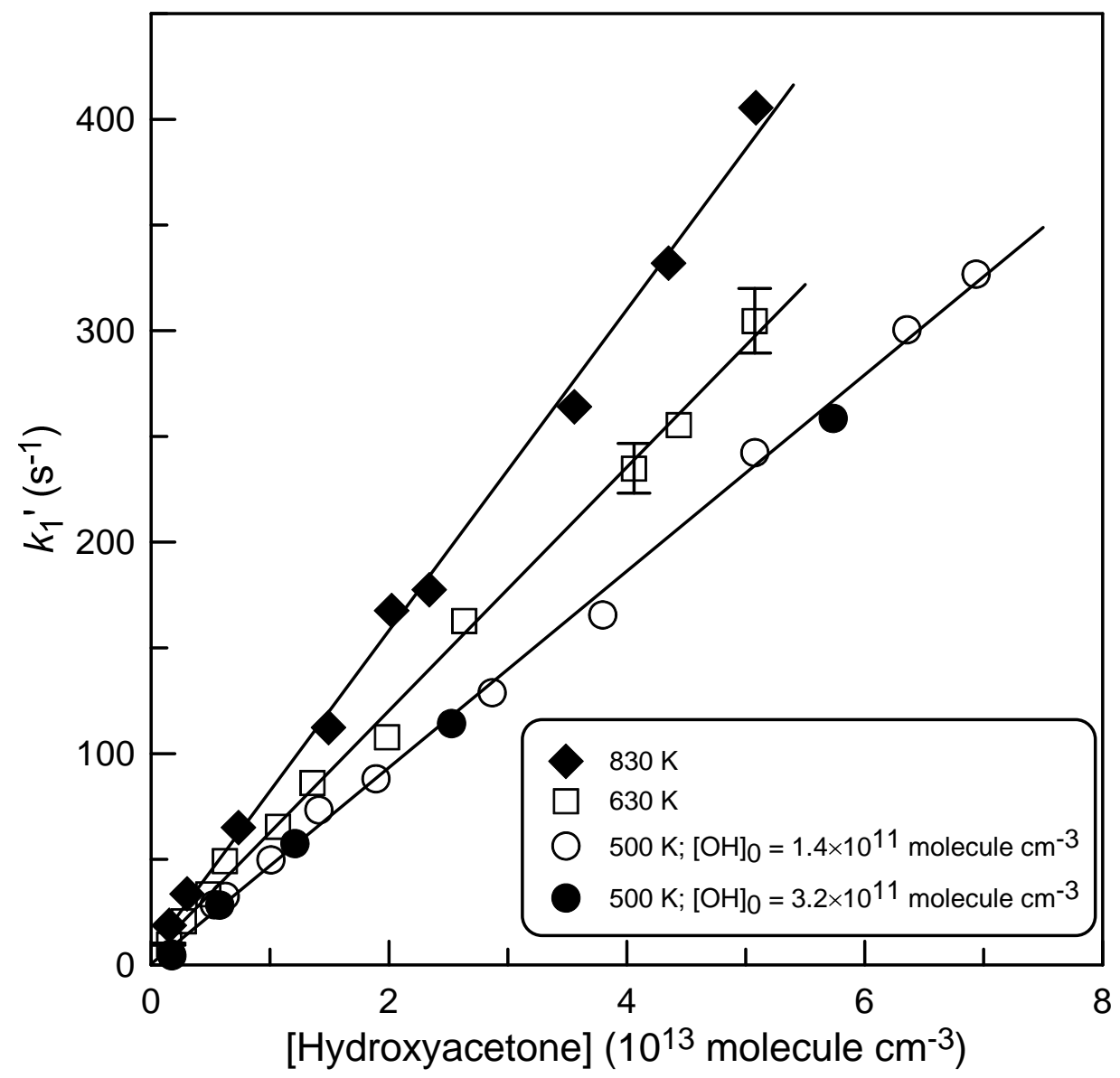

Figure 2. Dependence of the pseudo-first-order rate constant $\left(k_{1}{ }^{\prime}\right)$ on the concentration of hydroxyacetone at different temperatures. Error bars correspond to typical uncertainties $(\leq 5 \%)$ on the determination of $k_{1}{ }^{\prime}$. For clarity, $k_{1}{ }^{\prime}$ data at $\mathrm{T}=630$ and $500 \mathrm{~K}$ are $Y$-shifted by -20 and -45 $s^{-1}$, respectively.

The absolute measurements of $k_{1}$ have been carried out in an uncoated quartz reactor, except two temperatures, 298 and 336K, where Pyrex reactor coated with halocarbon wax was used. In the quartz reactor, the intercepts of the linear plots, like those shown in Figure $2, k_{\mathrm{w}}$, were found to decrease with increasing temperature (from 60 to $10 \mathrm{~s}^{-1}$ between 330 and $830 \mathrm{~K}$ ) and to be significantly higher (particularly at low temperatures) compared with the rate of $\mathrm{OH}$ decay measured in the absence of hydroxyacetone in the reactor $\left(k_{\mathrm{w}} \sim 10 \mathrm{~s}^{-1}\right.$, independent of temperature). Similar behavior was observed in a Pyrex reactor coated with halocarbon wax: 
the intercepts observed at $\mathrm{T}=336$ and $298 \mathrm{~K}$ were found to be about $20 \mathrm{~s}^{-1}$ (Figure S3, SI) and increased at lower temperatures. Baasandorj et al. ${ }^{14}$ reported a similar effect in their study of reaction (1) in a reactor coated with halocarbon wax: upon addition of hydroxyacetone some experimental pseudo-first-order decays of $\mathrm{OH}$ were nonlinear and large positive intercepts on the second order plots were observed. The observation was tentatively attributed to the heterogeneous reaction between $\mathrm{OH}$ radicals and hydroxyacetone adsorbed to the walls of the reactor. In order to avoid the heterogeneous complications, the authors ${ }^{14}$ carried out the measurements with addition of oxygen $\left((2-5) \times 10^{15} \mathrm{~cm}^{-3}\right)$ which appeared to minimize the hydroxyacetone-catalyzed heterogeneous loss of $\mathrm{OH}$. In the present study, we have not observed significant influence of oxygen addition on the kinetics of $\mathrm{OH}$, and the reaction rate constant was determined from the slope of the linear fit to the experimental data (straight lines in Figures 2 and S3), that is under assumption that heterogeneous contribution to the loss of $\mathrm{OH}$ radicals is independent of hydroxyacetone concentration in the gas phase and considering that the intercepts are relatively low compared with the measured maximum values of $k_{1}{ }^{\prime}$. The lowest temperature in the absolute measurements of $k_{1}$ was limited to $298 \mathrm{~K}$. It can be noted that very close values of $k_{1}$ (see Table 1 ) were measured at $\mathrm{T}=330 \mathrm{~K}$ in the uncoated quartz reactor (with intercept of $\approx 60 \mathrm{~s}^{-1}$ ) and at $\mathrm{T}=336 \mathrm{~K}$ in the halocarbon wax coated reactor (with intercept of $\approx 20 \mathrm{~s}^{-1}$ ). The results of the absolute measurements of $k_{1}$ are displayed in Table 1 . The combined uncertainty on $k_{1}$ was estimated to be approximately $15 \%$ by adding in quadrature the uncertainties on the absolute concentration of hydroxyacetone $(\sim 10 \%)$, on the measurements of the flows $(3 \%)$, pressure $(2 \%)$, temperature $(1 \%)$ and statistical error $(\leq$ $5 \%)$.

3.2. Rate constant of reaction (1): relative measurements. Considering the potential heterogeneous complications in the absolute measurements of the reaction rate constant, we have conducted two series of the relative rate measurements with reactions of $\mathrm{OH}$ with $\mathrm{Br}_{2}$ and $\mathrm{OH}+\mathrm{n}$-heptane as a reference. In the experiments with $\mathrm{OH}+\mathrm{Br}_{2}$ as a reference reaction, the initial concentration of $\mathrm{OH}$ radicals, $[\mathrm{OH}]_{0}$, was titrated by a mixture of $\mathrm{Br}_{2}$ and $\mathrm{HAC}$ and the concentration of $\mathrm{HOBr}$ was measured as a function of the $[\mathrm{HAC}] /\left[\mathrm{Br}_{2}\right]$ ratio:

$$
\begin{aligned}
& \mathrm{OH}+\mathrm{CH}_{3} \mathrm{C}(\mathrm{O}) \mathrm{CH}_{2} \mathrm{OH} \rightarrow \text { products } \\
& \mathrm{OH}+\mathrm{Br}_{2} \rightarrow \quad \mathrm{HOBr}+\mathrm{Br}
\end{aligned}
$$

The concentration of $\mathrm{HOBr}$ formed corresponds to the fraction of $[\mathrm{OH}]_{0}$ consumed in reaction with $\mathrm{Br}_{2}$ :

$$
[\mathrm{HOBr}]=\frac{k_{3}\left[\mathrm{Br}_{2}\right]}{k_{3}\left[\mathrm{Br}_{2}\right]+k_{1}[\mathrm{HAC}]+k_{w}} \times[\mathrm{OH}]_{0}
$$


Rearrangement of this expression leads to:

$$
\frac{[\mathrm{OH}]_{0}}{[\mathrm{HOBr}]}-1=\frac{k_{1}[\mathrm{HAC}]}{k_{3}\left[\mathrm{Br}_{2}\right]}+\frac{k_{w}}{k_{3}\left[\mathrm{Br}_{2}\right]}
$$

In order to keep the contribution of the second term in equation (I) constant, the experiments were carried out at a constant concentration of $\mathrm{Br}_{2} . k_{1} / k_{3}$ ratios were derived from the plots of $\left([\mathrm{OH}]_{0} /[\mathrm{HOBr}]-1\right)$ as a function of the $[\mathrm{HAC}] /\left[\mathrm{Br}_{2}\right]$ ratio. In the experiments, $\mathrm{HOBr}$ was monitored in both HAC -free system, corresponding to $[\mathrm{OH}]_{0}$, and in the $\mathrm{Br}_{2}$ and $\mathrm{HAC}$ containing system, corresponding to the fraction of $[\mathrm{OH}]_{0}$ reacted with $\mathrm{Br}_{2}$. The measurements were carried out at a total pressure of nearly 2 Torr of $\mathrm{He}$ in the reactor. Initial concentration of $\mathrm{OH}$ radicals was in the range $(2-6) \times 10^{11}$ molecule $\mathrm{cm}^{-3}$, reaction time was $(0.02-0.05) \mathrm{s}$, concentrations of $\mathrm{Br}_{2}$ and hydroxyacetone are shown in Table 2. Examples of the experimental data are displayed in Figures 3 and S4 (SI). The values of $k_{1} / k_{3}$ at different temperatures were derived from the slopes of the linear dependences in Figures 3 and S4, according to equation (I). Final values of $k_{1}$ (Table 2) were calculated with $k_{3}=2.16 \times 10^{-11}$ $\exp (207 / \mathrm{T}) \mathrm{cm}^{3}$ molecule $\mathrm{e}^{-1} \mathrm{~s}^{-1}$ which is well established in the temperature range $220-950 \mathrm{~K}^{7}$ One can note that two linear plots in Figure 3, corresponding to the experimental data obtained at $\mathrm{T}=750 \mathrm{~K}$ with different concentrations of $\mathrm{Br}_{2}$, have similar slopes (i.e. provide similar $k_{1} / k_{3}$ ratios) and different intercepts in agreement with equation (I). 


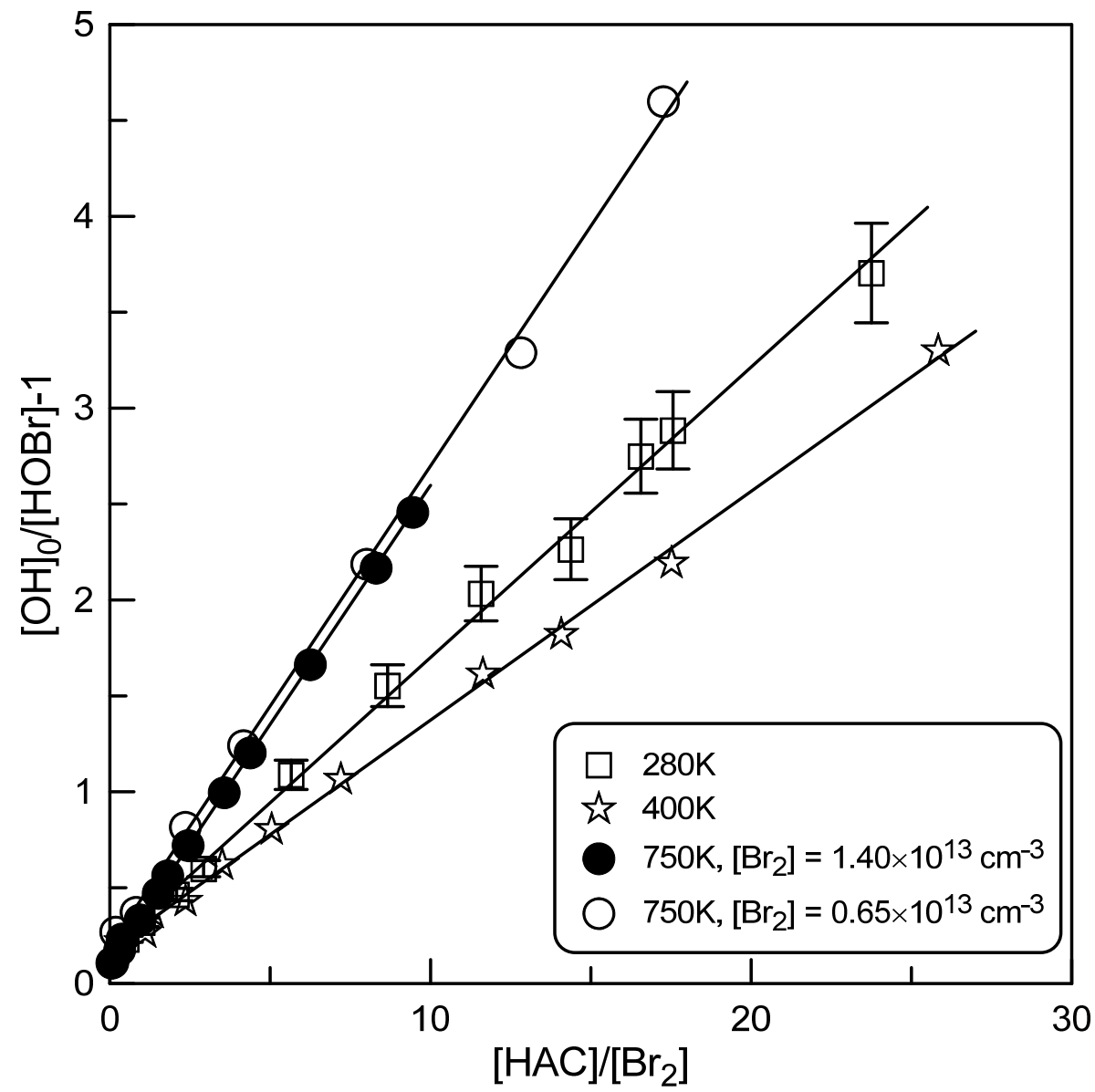

Figure 3. $\mathrm{HOBr}$ formed upon $\mathrm{OH}$ consumption by $\mathrm{Br}_{2}+\mathrm{HAC}$ mixtures at different temperatures. The error bars represent typical uncertainties of the measurements $(\leq 10 \%)$.

Table 2. Summary of the Relative Measurements of the Rate Constant of the Reaction $\mathrm{OH}+$ hydroxyacetone with reaction $\mathrm{OH}+\mathrm{Br}_{2}$ as a reference.

$\begin{array}{cccccc}T(\mathrm{~K})^{a} & \text { No./exp. } .^{b} & {[\mathrm{HAC}]^{c}} & {\left[\mathrm{Br}_{2}\right]^{c}} & k_{1} / k_{3} & k_{1}{ }^{d} \\ 250 & 10 & 2.33-38.6 & 2.61 & 0.171 & 8.45 \\ 265 & 11 & 1.71-29.9 & 2.09 & 0.152 & 7.17 \\ 280 & 11 & 0.92-43.0 & 1.88 & 0.151 & 6.83 \\ 301 & 8 & 2.42-49.7 & 2.35 & 0.140 & 6.02 \\ 310 & 8 & 1.94-27.6 & 1.71 & 0.138 & 5.81 \\ 350 & 12 & 0.39-29.7 & 1.52 & 0.119 & 4.64 \\ 400 & 11 & 0.27-19.1 & 0.76 & 0.119 & 4.31 \\ 465 & 12 & 0.21-21.8 & 1.00 & 0.133 & 4.48 \\ 510 & 10 & 0.11-18.0 & 1.07 & 0.149 & 4.83 \\ 555 & 12 & 0.17-15.4 & 0.90 & 0.178 & 5.58 \\ 690 & 9 & 0.60-12.1 & 1.57 & 0.231 & 6.74 \\ 750 & 20 & 0.11-12.9 & 0.65-1.40 & 0.249 & 7.09\end{array}$

${ }^{a} \mathrm{~T}=250-301 \mathrm{~K}$ : halocarbon wax coated reactor; $\mathrm{T}=310-750 \mathrm{~K}$ : uncoated quartz reactor. ${ }^{b}$ Number of data points. ${ }^{c}$ Units of $10^{13}$ molecule $\mathrm{cm}^{-3}$. ${ }^{d}$ Units of $10^{-12} \mathrm{~cm}^{3}$ molecule ${ }^{-1} \mathrm{~s}^{-1}$, estimated uncertainty on $k_{1}$ is nearly $20 \%$. 
In another series of experiments, the rate constant of reaction (1) was measured at two temperatures, $\mathrm{T}=290$ and $320 \mathrm{~K}$, and $\mathrm{P}=2.1$ Torr using the traditional relative rate method, which consisted of the measurements of the consumption of hydroxyacetone and reference compound, $n$-heptane, simultaneously present in the reactor, in reactions with $\mathrm{OH}$ :

$$
\begin{aligned}
& \mathrm{OH}+\mathrm{HAC} \rightarrow \text { Products } \\
& \mathrm{OH}+n \text {-heptane } \rightarrow \text { Products }
\end{aligned}
$$

The relative consumptions of HAC and $n$-heptane are defined by the rate constants of their reactions with $\mathrm{OH}$ :

$$
\ln \frac{[\mathrm{HAC}]_{0}}{[\mathrm{HAC}]}=\frac{k_{1}}{k_{4}} \times \ln \frac{[n-\text { heptane }]_{0}}{[n-\text { heptane }]}
$$

where the expressions under the logarithm are the ratios of the compound concentration in the absence of to that in the presence of $\mathrm{OH}$ radicals for a given reaction time.

In the experiments, the initial concentrations of $\mathrm{HAC}$ and $n$-heptane were in the range (4 $-6)$ and $(1-2) \times 10^{12}$ molecule $\mathrm{cm}^{-3}$, respectively. The concentration of $\mathrm{OH}$ radicals, formed through reaction (2) with $\left[\mathrm{NO}_{2}\right] \approx 5 \times 10^{13}$ molecule $\mathrm{cm}^{-3}$, was varied being $\sim 10^{13}$ molecule $\mathrm{cm}^{-}$ ${ }^{3}$ at maximum. Hydroxyacetone and $n$-heptane were monitored by mass spectrometry at their parent peaks at $\mathrm{m} / \mathrm{z}=74$ and 100 , respectively. It was verified that there was no interference between the mass spectra of these two species and that the products of their reactions with $\mathrm{OH}$ did not contribute to these peaks. Secondary reactions of HAC and $n$-heptane with organic radicals produced in reactions (1) and (4) are expected to be very slow at the low temperatures of the study. The observed independence of the experimental results of the reaction time, which was varied from 0.015 to $0.06 \mathrm{~s}$, seems to support this assumption. It can also be noted that the possible secondary chemistry initiated by oxygen atoms formed in the self-reaction of $\mathrm{OH}$ radicals,

$$
\mathrm{OH}+\mathrm{OH} \rightarrow \mathrm{O}+\mathrm{H}_{2} \mathrm{O}
$$

has a limited impact on the concentrations of HAC and $n$-heptane, because O-atoms are mainly consumed in the fast reactions with $\mathrm{OH}$ radicals and $\mathrm{NO}_{2}$ present in high concentrations in the reactor:

$$
\begin{aligned}
& \mathrm{O}+\mathrm{NO}_{2} \rightarrow \mathrm{NO}+\mathrm{O}_{2} \\
& k_{6}=9.85 \times 10^{-16} T^{1.41} \exp (543 / T) \mathrm{cm}^{3} \text { molecule }^{-1} \mathrm{~s}^{-1}(T=220-950 \mathrm{~K}),{ }^{24} \\
& \mathrm{O}+\mathrm{OH} \rightarrow \mathrm{H}+\mathrm{O}_{2} \\
& k_{7}=1.8 \times 10^{-11} \exp (180 / T) \mathrm{cm}^{3} \text { molecule }^{-1} \mathrm{~s}^{-1}(T=136-515 \mathrm{~K}),{ }^{25} \\
& \mathrm{H}+\mathrm{NO}_{2} \rightarrow \mathrm{OH}+\mathrm{NO}
\end{aligned}
$$


The observed dependences of $\ln \left([\mathrm{HAC}]_{0} /[\mathrm{HAC}]\right)$ on $\ln \left([n \text {-heptane }]_{0} /[n\right.$-heptane $\left.]\right)$ are presented in Figure 4. According to equation (II) the slopes of the straight lines in Figure 4 correspond to the $k_{1}$ to $k_{4}$ ratio. For the rate constant of the reference reaction (4) we have used $k_{4}=3.75 \times 10^{-16} \mathrm{~T}^{1.65} \exp (101 / \mathrm{T}) \mathrm{cm}^{3}$ molecule $\mathrm{e}^{-1} \mathrm{~s}^{-1}$ recommended at $\mathrm{T}=220-1300 \mathrm{~K}$ with uncertainty of $15 \% .{ }^{16}$ With $k_{4}$ calculated through this expression and $k_{1} / k_{4}( \pm 1 \sigma)=$ $1.093 \pm 0.006$ and $0.799 \pm 0.006$ derived from the slopes of the straight lines in Figure $4, k_{1}=$ $6.71 \times 10^{-12}$ and $5.59 \times 10^{-12} \mathrm{~cm}^{3}$ molecule $\mathrm{s}^{-1}$ at $\mathrm{T}=290$ and $320 \mathrm{~K}$, respectively, with estimated total uncertainty of $20 \%$, including that on the rate constant of the reference reaction.

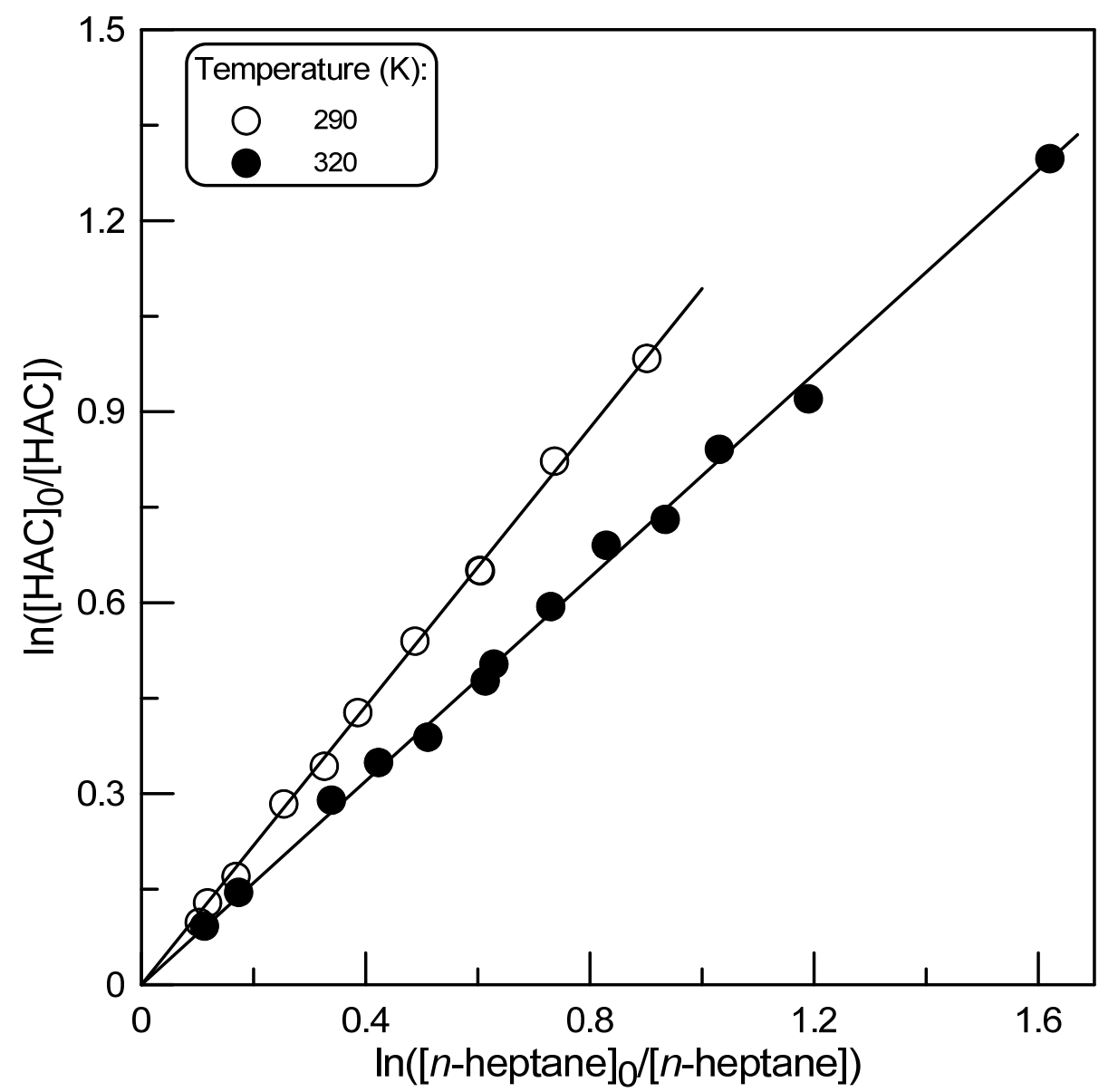

Figure 4. Dependence of $\ln \left([\mathrm{HAC}]_{0} /[\mathrm{HAC}]\right)$ on $\ln (\mathrm{n} \text {-heptane }]_{0} /[\mathrm{n}$-heptane $]$ ) observed at $\mathrm{P}=2.1$ Torr and $\mathrm{T}=$ 290 and $320 \mathrm{~K}$.

3.3. Rate constant of reaction (1): pressure dependence. The rate constant of reaction (1) was measured at total pressure of helium between 1.0 and 10.4 Torr and $\mathrm{T}=301 \mathrm{~K}$. This temperature was chosen for comparison with data of $\mathrm{Vu}$ et al. $^{8}$ who reported the measurements of $k_{1}$ at this temperature and pressures between 10 and 70 Torr. Relative rate 
methods, as described above, were applied in these measurements. The experimental data observed with the reaction of $\mathrm{OH}$ with $\mathrm{Br}_{2}$ as a reference are shown in Figure 5. One can note that the results obtained at different pressures are similar in the range of the experimental uncertainty. This results in very close values for $k_{1}$ at different pressures: 6.06, 6.02, 6.44 and $5.84 \times 10^{-12} \mathrm{~cm}^{3}$ molecule $\mathrm{s}^{-1}$ at $\mathrm{P}=1,2,5$ and 10.4 Torr of He, respectively, with estimated overall uncertainty on $k_{1}$ of $20 \%$.

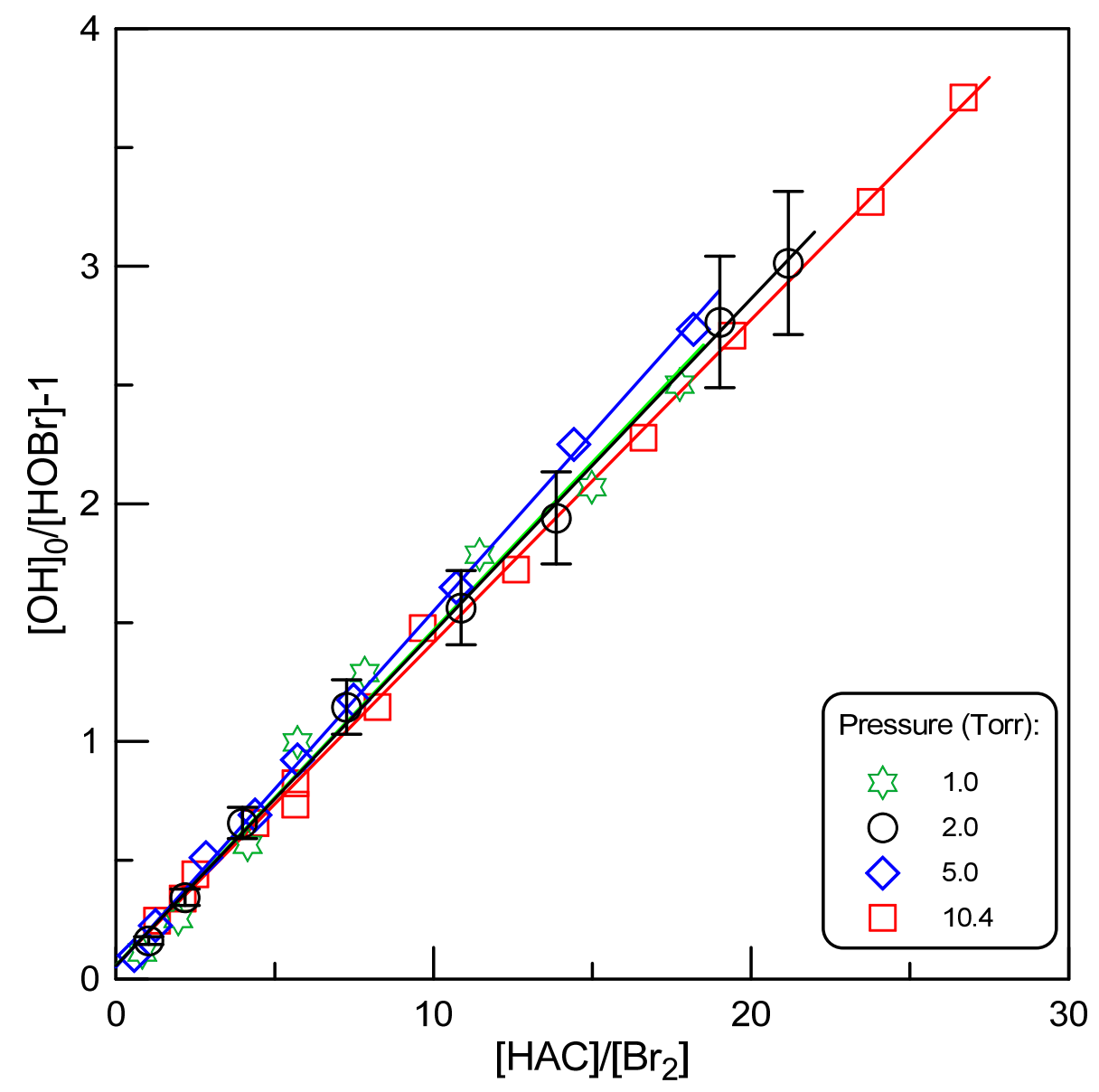

Figure 5. $\mathrm{HOBr}$ yield from $\mathrm{OH}$ radical titration with $\mathrm{Br}_{2}+\mathrm{HAC}$ mixtures at $\mathrm{T}=301 \mathrm{~K}$ and different pressures. The error bars represent typical uncertainties of the measurements $(\leq 10 \%)$.

Similar and independent of pressure values of $k_{1}$ were measured in the experiments using reaction of $\mathrm{OH}+n$-heptane as a reference (Figure 6). The values of $k_{1} / k_{4}=0.965,0.928$ and 0.911 derived from the data in Figure 6 result in $k_{1}=6.22,5.98$ and $5.87 \times 10^{-12} \mathrm{~cm}^{3}$ molecule ${ }^{1} \mathrm{~s}^{-1}$ at $\mathrm{P}=1.45,3.25$ and 7.6 Torr of He, respectively. 


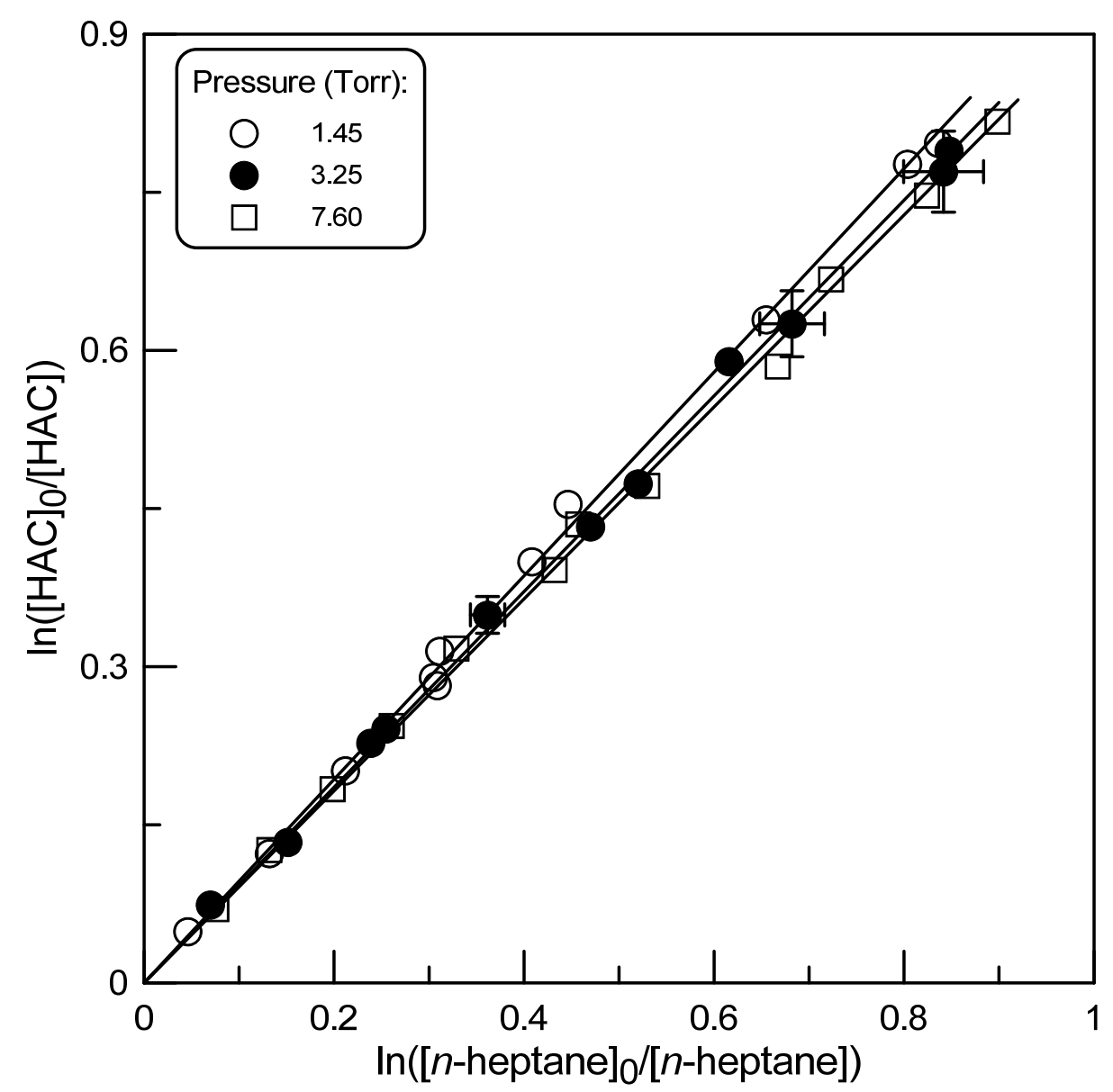

Figure 6. Dependence of $\ln \left([\mathrm{HAC}]_{0} /[\mathrm{HAC}]\right)$ on $\ln (\mathrm{n} \text {-heptane }]_{0} /[\mathrm{n}$-heptane $]$ ) observed at different pressures and $\mathrm{T}=301 \mathrm{~K}$. Partially shown error bars correspond to maximum uncertainty of $5 \%$ on the measurements.

All the data obtained for $k_{1}$ at $\mathrm{T}=301 \mathrm{~K}$ and different pressures are displayed in Figure 7 in line with those reported by $\mathrm{Vu}$ et al. ${ }^{8}$ The present measurements do not show any pressure dependence in the pressure range from 1 to 10.4 Torr and are very close to $k_{1}$ data measured by $\mathrm{Vu}$ et $\mathrm{al}^{8}$ at pressures $30-70$ Torr of He. Although our data do not confirm a trend of decrease of $k_{1}$ with decreasing pressure observed by $\mathrm{Vu}$ et al., ${ }^{8}$ they do not exclude the hypothetical dependence of $k_{1}$ on pressure at higher pressures if $k_{1}$ is in a low pressure limit in the pressure range ( $1-10$ Torr) of the present study. Unfortunately, the configuration of the use of the electron impact ionization mass spectrometer in the present work did not allow kinetic measurements at higher pressures.

It can be noted that in another low pressure study of Baasandorj et al., ${ }^{14}$ the reaction rate constant was also found to be independent of pressure between 2 and 5 Torr of He and to be in good agreement with room temperature measurements of $k_{1}$ by Dagaut et al. ${ }^{9}$ and Orlando et al. ${ }^{10}$ at 750 Torr of synthetic air, Chowdhury et al. ${ }^{11}$ at 10-90 Torr of Ar and Butkovskaya et al. at 200 Torr of $\mathrm{N}_{2}{ }^{12}$ However, these data cannot be used as an argument against the 
dependence of the rate constant on pressure, given the expected weak pressure dependence and a relatively large scatter in the existing experimental data (up to a factor of 2 at room temperature, as discussed below).

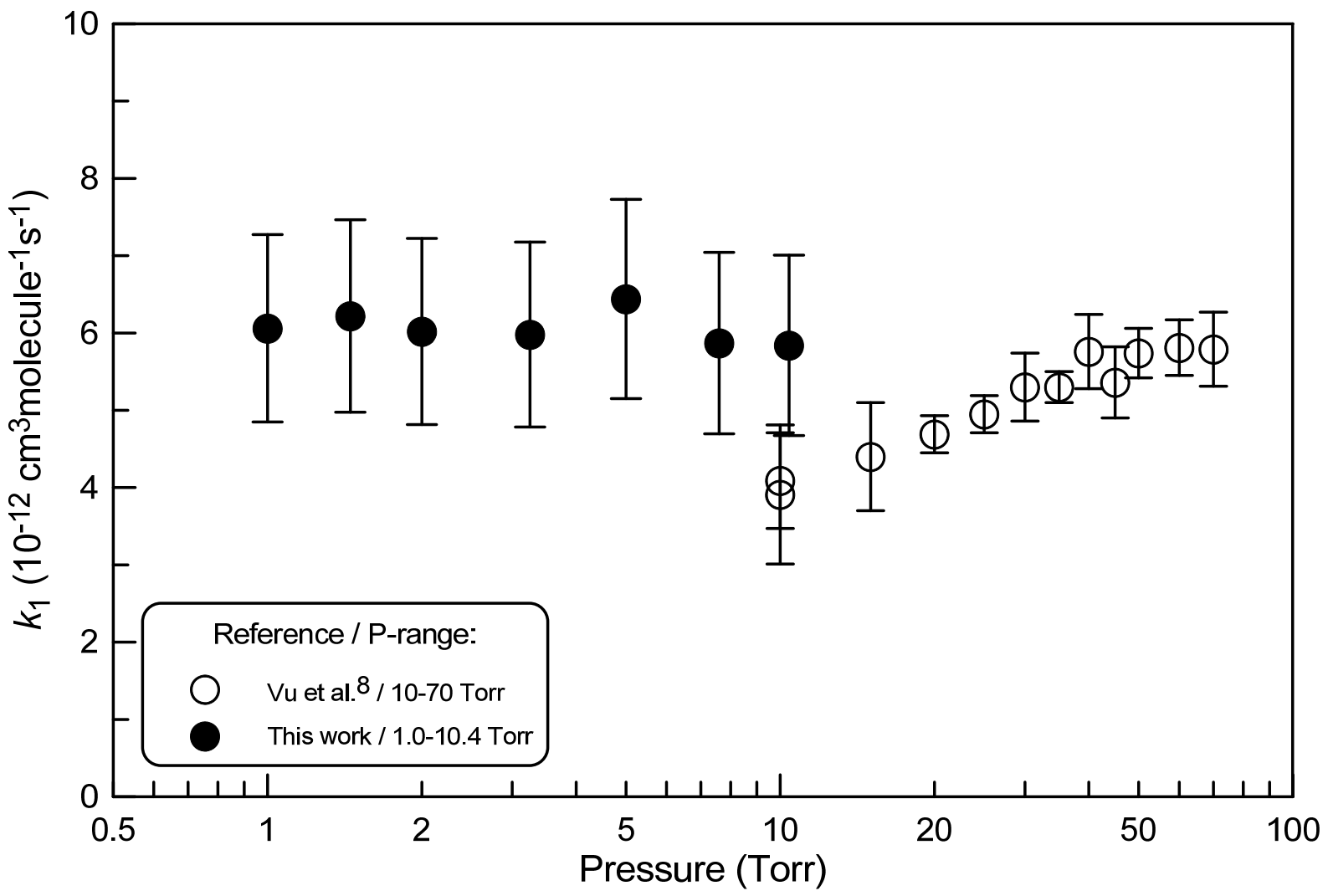

Figure 7. Reaction $\mathrm{OH}+\mathrm{CH}_{3} \mathrm{C}(\mathrm{O}) \mathrm{CH}_{2} \mathrm{OH}$ : pressure dependence of the reaction rate constant at $\mathrm{T}=301 \mathrm{~K}$.

3.4. Comparison with previous studies. The results of the previous and present measurements of $k_{1}$ are shown in Figure 8. As one can see, the present study confirms negative and U-shaped temperature dependences of $k_{1}$ reported previously by Dillon et al. (T $=233-363 \mathrm{~K})^{13}$ and $\mathrm{Vu}$ et al. $(\mathrm{T}=293-498 \mathrm{~K}){ }^{8}$ respectively. The results of the three studies are also in excellent agreement on the absolute basis. Both previous studies ${ }^{8,13}$ of reaction (1) were carried out using pulsed laser photolysis coupled with pulsed laser induced fluorescence detection of $\mathrm{OH}$ radicals. Dillon et al. ${ }^{13}$ reported $k_{1}=(2.15 \pm 0.3) \times 10^{-12} \exp ((305 \pm 10) / \mathrm{T})$ $\mathrm{cm}^{3}$ molecule $\mathrm{s}^{-1} \mathrm{~s}^{-1}$ at $\mathrm{P}=60$ Torr of He. Vu et al. ${ }^{8}$ observed that, at a pressure of 50 Torr of $\mathrm{He}$, the rate coefficient obeys a negative temperature dependence for temperatures between 290 and $380 \mathrm{~K}, k_{1}=(1.77 \pm 0.19) \times 10^{-12} \exp ((353 \pm 36) / \mathrm{T}) \mathrm{cm}^{3}$ molecule $\mathrm{s}^{-1}$, and a positive one, $k_{1}$ $=(1.14 \pm 0.25) \times 10^{-11} \exp (-(378 \pm 102) / \mathrm{T}) \mathrm{cm}^{3} \mathrm{molecule}^{-1} \mathrm{~s}^{-1}$, in the temperature range $410-500$ $\mathrm{K}$. The values of $k_{1}$ reported by Dillon et al., ${ }^{13} \mathrm{Vu}$ et al. ${ }^{8}$ and in the present work at $\mathrm{T}=298 \mathrm{~K}$ 
are approximately a factor of two higher compared with those reported in earlier room temperature studies ${ }^{9-12}$ and by Baasandorj et al. ${ }^{14}$ Dillon et al. ${ }^{13}$ and Baasandorj et al. ${ }^{14}$ carried out a detailed analysis of the possible errors due to the measurements of the absolute concentrations of hydroxyacetone, including uncertainties on its absorption cross section, presence of impurities and the regeneration of $\mathrm{OH}$; nevertheless, the cause of the disagreement between two sets of $k_{1}$ measurements remains unclear.

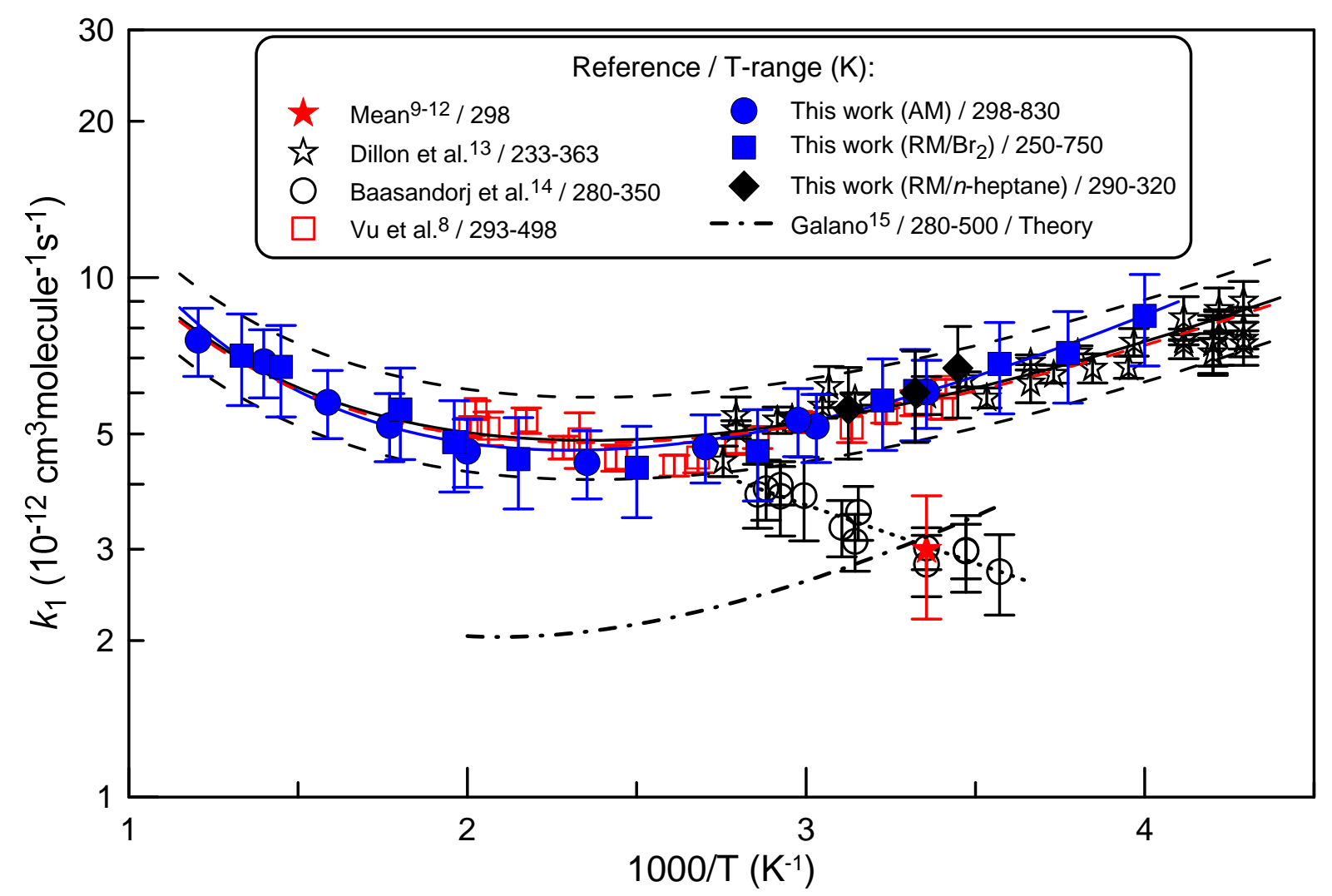

Figure 8. Reaction $\mathrm{OH}+\mathrm{CH}_{3} \mathrm{C}(\mathrm{O}) \mathrm{CH}_{2} \mathrm{OH}$ : temperature dependence of the reaction rate constant. AM: absolute measurement, RM: relative rate method. The error bars for the present data correspond to estimated 15 and $20 \%$ uncertainty on the measurements of $k_{1}$ by absolute and relative rate method, respectively; uncertainties on previous measurements are given as reported in respective studies. Lines correspond to the fit with modified Arrhenius expression, $k=A \times T^{n} \times \exp \left(-E_{a} / R T\right)$, of the data from the present study (solid blue line), the present study combined with those of Dillon et al. ${ }^{13}$ and $\mathrm{Vu}$ et al. ${ }^{8}$ (black solid line) with $20 \%$ uncertainty (dashed black lines) and to theory-based expression proposed by Vu et al. ${ }^{8}$ (red dashed line).

As one can see in Figure 8, the opposite trend in temperature dependence was observed by Dillon et al., ${ }^{13} \mathrm{Vu}$ et al. ${ }^{8}$ and in the present study compared to Baasandorj et al., ${ }^{14}$ who observed a positive temperature dependence of $k_{1}=(1.88 \pm 0.75) \times 10^{-11} \exp (-545 \pm 60 / \mathrm{T})$ $\mathrm{cm}^{3}$ molecule $\mathrm{s}^{-1}$ at $\mathrm{T}=280-350 \mathrm{~K}$ using a discharge-flow system coupled with resonance fluorescence detection of the $\mathrm{OH}$ radical. The reason for this discrepancy also remains unclear. Baasandorj et al. ${ }^{14}$ hypothesized that the use of different pressures might be a source 
of the difference between their results at $\mathrm{P}=2-5$ Torr and those of Dillon et al. ${ }^{13}$ at $\mathrm{P}=60$ Torr. Indeed, $\mathrm{Vu}$ et al. ${ }^{8}$ observed a pronounced decrease of $k_{1}$ at total pressures lower than $\sim 45$ Torr at $\mathrm{T}=301 \mathrm{~K}$ (Figure 7) and rationalized the pressure dependence of $k_{1}$ in the frame of the reaction mechanism including the formation of a hydrogen-bonded pre-reactive complex and its collisional thermalization at high pressures. However, the results of the present study do not seem to support the pressure dependence of the reaction rate constant, and in this sense, raise more questions than give answers. Firstly, we have not observed any appreciable pressure dependence of $k_{1}$ in the pressure range 1-10.4 Torr (Figure 7). Secondly, our low pressure data (at $\mathrm{P} \approx 2$ Torr of $\mathrm{He}$ ) for $k_{1}$ are in excellent agreement in the whole temperature range with those of Dillon et al. ${ }^{13}$ and $\mathrm{Vu}$ et al. ${ }^{8}$ measured at $\mathrm{P}=60$ and 50 Torr, respectively. In our opinion, a relatively weak pressure dependence of $k_{1}$, if exists, can be masked by non-identified pressure independent systematic errors (up to a factor of 2 at room temperature) in some of the available studies.

A fit to the present data with modified Arrhenius expression, $k=\mathrm{A} \times T^{\mathrm{n}} \times \exp \left(-E_{\mathrm{a}} / \mathrm{R} T\right)$, provides (blue line in Figure 8):

$$
k_{1}=4.7 \times 10^{-22} \times T^{3.25} \exp (1410 / \mathrm{T}) \mathrm{cm}^{3} \text { molecule } \mathrm{s}^{-1} \text { at } \mathrm{T}=250-830 \mathrm{~K} .
$$

If our data are combined with those of Dillon et al. ${ }^{13}$ and $\mathrm{Vu}$ et al., ${ }^{8}$ one gets (black solid line in Figure 8):

$$
k_{1}=4.4 \times 10^{-20} \times T^{2.63} \exp (1110 / \mathrm{T}) \mathrm{cm}^{3} \text { molecule } \mathrm{s}^{-1} \text { at } \mathrm{T}=230-830 \mathrm{~K} \text {. }
$$

The dashed black lines in Figure 8 correspond to $\pm 20 \%$ deviation from this expression, showing that all temperature data from these three temperature dependent measurements of $k_{1}$ fall into this range. Based on this and considering very good agreement between the $k_{1}$ data from Dillon et al., ${ }^{13} \mathrm{Vu}$ et al. ${ }^{8}$ and present study, obtained under different experimental conditions and with different experimental methods, we would recommend the above expression for $k_{1}$ to use in the temperature range $230-830 \mathrm{~K}$ with independent of temperature $20 \%$ uncertainty. Interestingly, the temperature dependence of $k_{1}$ described by this expression is almost indistinguishable from that corresponding to the theory-based expression $k_{1}=$ $5.3 \times 10^{-20} \times T^{2.6} \exp (1100 / \mathrm{T}) \mathrm{cm}^{3} \mathrm{molecule}^{-1} \mathrm{~s}^{-1}$ (red dashed line in Figure 8) which was proposed by $\mathrm{Vu}$ et al. $^{8}$ to represent their high-pressure $k_{1}$ data and those of Dillon et al. ${ }^{13}$ over the combined range $230-500 \mathrm{~K}$. It can be noted also that the results of theoretical study of Galano, ${ }^{15}$ reporting $k_{1}=5.29 \times 10^{-23} \times T^{3.4} \exp (1623 / \mathrm{T}) \mathrm{cm}^{3} \mathrm{molecule}^{-1} \mathrm{~s}^{-1}$ at $\mathrm{T}=280-500 \mathrm{~K}$, reproduce quite well the temperature dependence of $k_{1}$ (Figure 8 ) observed by Dillon et al., ${ }^{13}$ $\mathrm{Vu}$ et $\mathrm{al}^{8}{ }^{8}$ and in the present study, although with the absolute values of $k_{1}$ approximately twice smaller. 
The present study, as one can see in Figure 8, strongly supports two ${ }^{8,13}$ of three previous temperature dependent measurements of $k_{1}$. However the reason for the disagreement with earlier room temperature studies ${ }^{9-12}$ and that of Baasandorj et al. ${ }^{14}$ remains unclear and even somewhat mysterious, given the very low scatter of $k_{1}$ measurements for both lower ${ }^{9-12,14}$ and higher (refs. 8,13 and present work) values of $k_{1}$ reported at $\mathrm{T}=298 \mathrm{~K}$. The reaction of $\mathrm{OH}$ radicals seems to be a rare case where almost all the data for the reaction rate constant were determined using the absolute measurements (except one room temperature study ${ }^{10}$ and the present work). It seems that an in-depth study (even if only at room temperature) employing a relative rate method for the measurements of $k_{1}$ at high pressure would be helpful to verify once again the pressure dependence of $k_{1}$ and for the arbitration between the low and high values of the rate constant at $\mathrm{T}<350 \mathrm{~K}$.

\section{CONCLUSIONS}

In this work, we examined the kinetics of the reaction of $\mathrm{OH}$ radicals with hydroxyacetone using a discharge flow reactor combined with an electron impact ionization mass spectrometer. The total rate constant of the reaction, $k_{1}=4.7 \times 10^{-22} \times T^{3.25} \exp (1410 / \mathrm{T})$ $\mathrm{cm}^{3}$ molecule $\mathrm{s}^{-1}$, was determined using both relative rate and absolute methods in the temperature range $250-830 \mathrm{~K}$. The present data combined with selected previous temperature dependent studies ${ }^{8,13}$ of the reaction (1) yield $k_{1}=4.4 \times 10^{-20} \times T^{2.63} \exp (1110 / \mathrm{T}) \mathrm{cm}^{3}$ molecule $\mathrm{s}^{-1}$ 1 , which is recommended from the present work at $\mathrm{T}=230-830 \mathrm{~K}$ (with conservative uncertainty of $20 \%$ at all temperatures). The U-shaped temperature dependence of $k_{1}$ observed in the present work at 2 Torr total pressure of $\mathrm{He}$ is in excellent agreement with two previous studies $^{8,13}$ of reaction (1) at $\mathrm{P}=50-60$ Torr in contrast to the positive temperature dependence observed by Baasandorj et al. ${ }^{14}$ at $\mathrm{T}=280-350 \mathrm{~K}$ and $\mathrm{P}=2-5$ Torr. In addition, the present measurements provide by a factor of 2 higher value of $k_{1}$ at $\mathrm{T}=298 \mathrm{~K}$ compared with those reported in earlier room temperature studies. ${ }^{9-12}$ The reasons for these disagreements remain unclear. The present results do not support the hypothesis that the divergence between low and high pressure temperature dependent studies is due to dependence of $k_{1}$ on pressure. ${ }^{8}$

\section{ASSOCIATED CONTENT}

\section{Supporting Information}

Diagram of the high temperature flow reactors (Figure S1); Kinetics of $\mathrm{OH}$ consumption at $\mathrm{T}$ $=330 \mathrm{~K}$ (Figure S2); Second-order plots for the $\mathrm{OH}+$ hydroxyacetone reaction at $\mathrm{T}=298$, 
336 and $370 \mathrm{~K}$ (Figure $\mathrm{S} 3$ ); $\mathrm{HOBr}$ yield from $\mathrm{OH}$ radical titration with $\mathrm{Br}_{2}$ + hydroxyacetone mixtures at $\mathrm{T}=165,465$ and $555 \mathrm{~K}$ (Figure $\mathrm{S} 4$ ).

\section{ACKNOWLEDGEMENT}

This work was partly supported by the French national program LEFE/INSU. 


\section{REFERENCES}

(1) Calvert, J.; Mellouki, A.; Orlando, J.; Pilling, M.; Wallington, T., Mechanisms of Atmospheric Oxidation of the Oxygenates. Oxford University Press: New York, 2011.

(2) Christian, T. J.; Kleiss, B.; Yokelson, R. J.; Holzinger, R.; Crutzen, P. J.; Hao, W. M.; Saharjo, B. H.; Ward, D. E. Comprehensive Laboratory Measurements of Biomass-Burning Emissions: 1. Emissions from Indonesian, African, and other Fuels. J. Geophys. Res.: Atmospheres 2003, 108, 4719.

(3) Karl, T.; Guenther, A.; Turnipseed, A.; Tyndall, G.; Artaxo, P.; Martin, S. Rapid Formation of Isoprene Photo-Oxidation Products Observed in Amazonia. Atmos. Chem. Phys. 2009, 9, 7753-7767.

(4) Paulot, F.; Crounse, J. D.; Kjaergaard, H. G.; Kroll, J. H.; Seinfeld, J. H.; Wennberg, P. O. Isoprene Photooxidation: New Insights Into the Production of Acids and Organic Nitrates. Atmos. Chem. Phys. 2009, 9, 1479-1501.

(5) Galloway, M. M.; Huisman, A. J.; Yee, L. D.; Chan, A. W. H.; Loza, C. L.; Seinfeld, J. H.; Keutsch, F. N. Yields of Oxidized Volatile Organic Compounds During the OH Radical Initiated Oxidation of Isoprene, Methyl Vinyl Ketone, and Methacrolein under High $\mathrm{NO}_{\mathrm{X}}$ Conditions. Atmos. Chem. Phys. 2011, 11, 10779-10790.

(6) Crounse, J. D.; Knap, H. C.; Ørnsø, K. B.; Jørgensen, S.; Paulot, F.; Kjaergaard, H. G.; Wennberg, P. O. Atmospheric Fate of Methacrolein. 1. Peroxy Radical Isomerization Following Addition of $\mathrm{OH}$ and $\mathrm{O}_{2}$. J. Phys. Chem. A 2012, 116, 5756-5762.

(7) Bedjanian, Y. Temperature-Dependent Rate Constant for the Reaction of Hydroxyl Radical with 3-Hydroxy-3-methyl-2-butanone. J. Phys. Chem. A 2019, 123, 10446-10453.

(8) Vu, N. D.; Khamaganov, V.; Nguyen, V. S.; Carl, S. A.; Peeters, J. Absolute Rate Coefficient of the Gas-Phase Reaction between Hydroxyl Radical $(\mathrm{OH})$ and Hydroxyacetone: Investigating the Effects of Temperature and Pressure. J. Phys. Chem. A 2013, 117, 12208 12215.

(9) Dagaut, P.; Liu, R.; Wallington, T. J.; Kurylo, M. J. Kinetic Measurements of the GasPhase Reactions of Hydroxyl Radicals With Hydroxy Ethers, Hydroxy Ketones, and Keto Ethers. J. Phys. Chem. 1989, 93, 7838-7840.

(10) Orlando, J. J.; Tyndall, G. S.; Fracheboud, J.-M.; Estupiñan, E. G.; Haberkorn, S.; Zimmer, A. The Rate and Mechanism of the Gas-Phase Oxidation of Hydroxyacetone. Atmos. Environ. 1999, 33, 1621-1629. 
(11) Chowdhury, P. K.; Upadhyaya, H. P.; Naik, P. D.; Mittal, J. P. ArF Laser Photodissociation Dynamics of Hydroxyacetone: LIF Observation of $\mathrm{OH}$ and Its Reaction Rate with the Parent. Chem. Phys. Lett. 2002, 351, 201-207.

(12) Butkovskaya, N. I.; Pouvesle, N.; Kukui, A.; Mu, Y.; Le Bras, G. Mechanism of the OH-Initiated Oxidation of Hydroxyacetone over the Temperature Range 236-298 K. J. Phys. Chem. A 2006, 110, 6833-6843.

(13) Dillon, T. J.; Horowitz, A.; Hölscher, D.; Crowley, J. N.; Vereecken, L.; Peeters, J. Reaction of $\mathrm{HO}$ with Hydroxyacetone $\left(\mathrm{HOCH}_{2} \mathrm{C}(\mathrm{O}) \mathrm{CH}_{3}\right)$ : Rate Coefficients $(233-363 \mathrm{~K})$ and Mechanism. Phys. Chem. Chem. Phys. 2006, 8, 236-246.

(14) Baasandorj, M.; Griffith, S.; Dusanter, S.; Stevens, P. S. Experimental and Theoretical Studies of the Kinetics of the $\mathrm{OH}+$ Hydroxyacetone Reaction As a Function of Temperature. J. Phys. Chem. A 2009, 113, 10495-10502.

(15) Galano, A. Theoretical Study on the Reaction of Tropospheric Interest: Hydroxyacetone + OH. Mechanism and Kinetics. J. Phys. Chem. A 2006, 110, 9153-9160.

(16) Morin, J.; Romanias, M. N.; Bedjanian, Y. Experimental Study of the Reactions of $\mathrm{OH}$ Radicals with Propane, n-Pentane, and n-Heptane over a Wide Temperature Range. Int. J. Chem. Kinet. 2015, 47, 629-637.

(17) Bedjanian, Y.; Morin, J.; Romanias, M. N. Gas-Phase Reaction of Hydroxyl Radical with p-Cymene over an Extended Temperature Range. J. Phys. Chem. A 2015, 119, $11076-$ 11083.

(18) Braure, T.; Bedjanian, Y.; Romanias, M. N.; Morin, J.; Riffault, V.; Tomas, A.; Coddeville, P. Experimental Study of the Reactions of Limonene with OH and OD Radicals: Kinetics and Products. J. Phys. Chem. A 2014, 118, 9482-9490.

(19) Su, M. C.; Kumaran, S. S.; Lim, K. P.; Michael, J. V.; Wagner, A. F.; Harding, L. B.; Fang, D. C. Rate Constants, $1100 \leq \mathrm{T} \leq 2000 \mathrm{~K}$, for $\mathrm{H}+\mathrm{NO}_{2} \rightarrow \mathrm{OH}+\mathrm{NO}$ Using Two Shock Tube Techniques: Comparison of Theory to Experiment†. J. Phys. Chem. A 2002, 106, 82618270.

(20) Bedjanian, Y.; Le Bras, G.; Poulet, G. Kinetic Study of the Reactions of $\mathrm{Br}_{2}$ with $\mathrm{OH}$ and OD. Int. J. Chem. Kinet. 1999, 31, 698-704.

(21) Bedjanian, Y.; Le Bras, G.; Poulet, G. Kinetic Study of $\mathrm{OH}+\mathrm{OH}$ and OD + OD Reactions. J. Phys. Chem. A 1999, 103, 7017-7025.

(22) Kaufman, F. Kinetics of Elementary Radical Reactions in the Gas Phase. J. Phys. Chem. 1984, 88, 4909-4917. 
(23) Ivanov, A. V.; Trakhtenberg, S.; Bertram, A. K.; Gershenzon, Y. M.; Molina, M. J. $\mathrm{OH}, \mathrm{HO}_{2}$, and Ozone Gaseous Diffusion Coefficients. J. Phys. Chem. A 2007, 111, $1632-$ 1637.

(24) Bedjanian, Y.; Kalyan, C., Rate Constants of the Reactions of $\mathrm{O}\left({ }^{3} \mathrm{P}\right)$ Atoms with $\mathrm{Br}_{2}$ and $\mathrm{NO}_{2}$ over the Temperature Range 220-950 K. Int. J. Chem. Kinet. 2019, 51, 476-483.

(25) Burkholder, J. B.; Sander, S. P.; Abbatt, J.; Barker, J. R.; Huie, R. E.; Kolb, C. E.; Kurylo, M. J.; Orkin, V. L.; Wilmouth, D. M.; Wine, P. H. Chemical Kinetics and Photochemical Data for Use in Atmospheric Studies, Evaluation No. 18, JPL Publication 1510, Jet Propulsion Laboratory. http://jpldataeval.jpl.nasa.gov (accessed February 2020). 
TOC GRAPHIC

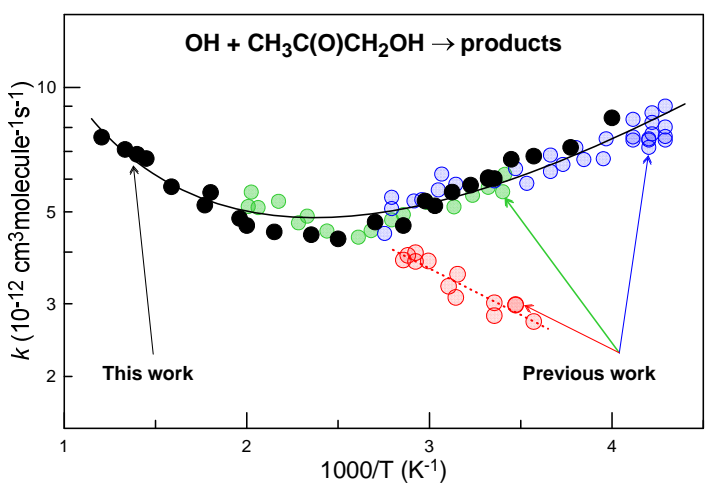

